Smith, G.C., T.F. Rees, P. MacCarthy, and S.R. Daniel. 1986. On the interpretation of schubert plot slopes for metal-humate systems. Soil Sci. 141:7-9.

Snoeyink, V.L., and D. Jenkins. 1980. Water chemistry. John Wiley \& Sons, New York.

Sparks, D.L. 1995. Environmental soil chemistry. Academic Press, San Diego, CA.

Sposito, G., K.M. Holtzclaw, and C.S. LeVesque-Madore. 1979. Cupric ion complexation by fulvic acid extracted from sewage sludgesoil mixtures. Soil Sci. Soc. Am. J. 43:1148-1155.

Stevenson, F.J. 1976. Stability constants of $\mathrm{Cu}^{2+}, \mathrm{Pb}^{2+}$, and $\mathrm{Cd}^{2+}$ complexes with humic acids. Soil Sci. Soc. Am. J. 40:665-672

Tan, H., J.T. Champion, J.F. Artiola, M.L. Brusseau, and R.M. Miller. 1994. Complexation of cadmium by a rhamnolipid biosurfactant Environ. Sci. Technol. 28:2402-2406.
Torrens, J.L., D.C. Herman, and R.M. Miller. 1998. Biosurfactant (rhamnolipid) sorption and the impact on rhamnolipid-facilitated removal of cadmium from various soils. Environ. Sci. Technol. 32:776-781.

Westall, J.C., J.L. Zachary, and F.M.M. Morel. 1976. MINEQL: A computer program for the calculation of chemical equilibrium composition of aqueous systems. Tech. Note no. 18. EPA Grant no. R-803738. Dep. of Civil Eng., Massachusetts Inst. of Technol., Cambridge, MA.

Zhang, Y., and R.M. Miller. 1992. Enhanced octadecane dispersion and biodegradation by a Pseudomonas rhamnolipid surfactant (biosurfactant). Appl. Environ. Microbiol. 58:3276-3282.

Zhang, Y., and R.M. Miller. 1994. Effect of a Pseudomonas rhamnolipid biosurfactant on cell hydrophobicity and biodegradation of octadecane. Appl. Environ. Microbiol. 60:2101-2106.

\title{
Fractionation and Mobility of Copper, Lead, and Zinc in Soil Profiles in the Vicinity of a Copper Smelter
}

\author{
Cezary Kabala and Bal Ram Singh*
}

\begin{abstract}
Four soil profiles located near a copper smelter in Poland were investigated for the distribution and chemical fractions of $\mathrm{Cu}, \mathrm{Pb}$, and $\mathrm{Zn}$ and their mobility in relation to soil properties. Contamination with heavy metals was primarily restricted to surface horizons and the extent of contamination was 7- to 115-fold for $\mathrm{Cu}$, 30-fold for $\mathbf{P b}$, and 6-fold for $\mathrm{Zn}$ as compared with subsurface horizons. In the lesscontaminated fine-textured soil, the metals were distributed in the order: residual $>>$ Fe-Mn oxides occluded $>$ organically complexed $>$ exchangeable and specifically adsorbed, while the order for sandy soils was: residual $>$ organically complexed $>$ Fe-Mn oxides occluded $>$ exchangeable and specifically adsorbed. The contaminated surface horizons of these profiles showed no consistent pattern of metal distribution. However, the common features of highly contaminated soils were very low percentage of residual fraction and the dominance of the $\mathrm{NH}_{4} \mathrm{OAc}$ extractable fraction. The sum of mobile metal fractions was generally $<\mathbf{1 0} \%$ in subsurface horizons, while in the contaminated surface horizons these fractions made up $50 \%$ of the total metal contents. Soil properties contributed more to the relative distribution of the metal fractions in the studied profiles than did the distance and direction to the source of pollution. The amounts of metal extracted by $0.01 M \mathrm{CaCl}_{2}$ accounted for only a small part of the same metals extracted by $\mathrm{NH}_{4} \mathrm{OAc}$. The mobility indexes of metals correlated positively and significantly with the total content of metals and negatively with the clay content.
\end{abstract}

$\mathrm{T}$ HE distribution of heavy metals in soil profiles, inherited from the parent material, is continuously altered due to the natural turnover in the rock-soilplant system. Knowledge of the total contents of heavy metals present in soil horizons provides limited information about their potential behavior and bioavailability. Heavy metals are associated with various soil components in different ways, and these associations determine their mobility and availability (Kabata-Pendias and Pen-

C. Kabala, Inst. of Soil Sci., Agric. Univ. of Wroclaw, 50-357 Wroclaw, Grunwaldzka 53, Poland. B.R. Singh, Dep. of Soil and Water Sci., Agric. Univ. of Norway, P.O. Box 5028, 1432 Aas, Norway. Received 7 Apr. 2000. *Corresponding author (balram.singh@ijvf.nlh.no).

Published in J. Environ. Qual. 30:485-492 (2001). dias, 1992; Singh, 1997; Ahumada et al., 1999). Watersoluble and exchangeable forms are considered readily mobile and available to plants, while metals incorporated into crystalline lattices of clays appear relatively inactive. The other forms-precipitated as carbonate, occluded in $\mathrm{Fe}, \mathrm{Mn}$, and $\mathrm{Al}$ oxides, or complexed with organic matter-could be considered relatively active or firmly bound, depending upon the actual combination of physical and chemical properties of soil (Sposito et al., 1982; Shuman, 1985). Thus, soil texture (clay content), $\mathrm{pH}$, organic matter, and $\mathrm{Fe}-\mathrm{Mn}$ oxides have been found to be the most important soil properties and components influencing the lability and biological uptake of heavy metals (Iyengar et al., 1981; Narwal and Singh, 1998; Ma and Rao, 1997; Karczewska et al., 1998).

Generally, under natural conditions, only a small fraction of trace metals is present in plant-available form (Kabata-Pendias and Pendias, 1992). However, in some natural soils developed from metal-rich parent materials, as well as in contaminated soils, up to 30 to $60 \%$ of heavy metals can occur in easily labile forms (Kuo et al., 1983; He and Singh, 1993; Singh et al., 1995; Karczewska et al., 1998).

Several reagents (e.g., $\mathrm{CaCl}_{2}, \mathrm{NH}_{4} \mathrm{OAc}, \mathrm{NH}_{4} \mathrm{NO}_{3}$, and EDTA) have been used to extract the "mobile" or "bioavailable" forms of heavy metals with single extraction procedures (He and Singh, 1995; Karczewska et al., 1998; Christensen and Huang, 1999; Narwal et al., 1999). Single and sequential extractions provide information on potential mobility as well as bioavailability and plant uptake of trace elements (Iyengar et al., 1981; Shuman, 1990; Singh, 1997). Studies on the speciation of heavy metals in polluted soils using sequential extraction techniques have increased in recent years, because these simple techniques provide knowledge about metal affinity to the soil components and the strength with which they are bound to the matrix (Narwal et al., 1999). Unlike the single extraction technique, sequential extrac-

Abbreviations: MF, mobility factor. 
tion gives information about both mobile and stabile fractions of metals in soil, which evaluates the actual and potential mobility of metals. Numerous fractionation techniques have been used for sequential extraction of heavy metals in soils (Tessier et al., 1979; Sposito et al., 1982; Shuman, 1985). The techniques vary in the number of fractions extracted, as well as the order and kind of reagents used. In general, the fractionation schemes start with the weakest extractants and end with the strongest, most aggressive, and separate five to seven metal fractions.

Despite the applications, the method's usefulness remains questioned. The problems found by several authors (Shuman, 1985; Kim and Fergusson, 1991; Karczewska, 1996; Ahnstrom and Parker, 1999) were mainly related to following causes: (i) the limited selectivity of the extractants, (ii) redistribution of elements among phases during extraction, (iii) the diversity of extraction schemes and limited comparability of data obtained by several investigators. Using extractants in an improper order or under improper conditions can lead to overor underestimated fractions (Kim and Fergusson, 1991). Also, the traditional system of fraction classification may lead to some confusion, suggesting an unrealistic selectivity of the extractants used (Kim and Fergusson, 1991). The separation of metal species, however, is actually defined on an operational basis, and as such separation has been widely used in various environmental studies (Kennedy et al., 1997; Ahumada et al., 1999; Christensen and Huang, 1999; Narwal et al., 1999).

The soils surrounding metal mining and smelting sites have been exposed to high contamination with trace elements. Helmisaari et al. (1995) reported Cu concentrations in soils of up to $7600 \mathrm{mg} \mathrm{kg}^{-1}$ in the vicinity of a copper smelter in Finland. Within a zone of $1 \mathrm{~km}$ around copper smelters in southwestern Poland, Roszyk and Szerszen (1988) found 250 to $10000 \mathrm{mg} \mathrm{kg}^{-1}$ of $\mathrm{Cu}$, 90 to $18000 \mathrm{mg} \mathrm{kg}^{-1}$ of $\mathrm{Pb}, 0.3$ to $10.9 \mathrm{mg} \mathrm{kg}^{-1}$ of $\mathrm{Cd}$, and 55 to $4000 \mathrm{mg} \mathrm{kg}^{-1}$ of $\mathrm{Zn}$. Such abnormally high concentrations of trace metals in soil create concern for the normal functioning of the ecosystem.

The investigations on metal forms, particularly using sequential extractions, mainly concern surface soil horizons (Iyengar et al., 1981; He and Singh, 1995; Chlopecka et al., 1996; Ma and Rao, 1997; Ahumada et al., 1999). Studies of contaminated areas, however, require that the whole soil profile, including subsurface horizons, be investigated. This study was therefore undertaken to (i) investigate the distribution and chemical fractions of copper, lead, and zinc in selected profiles differing widely in soil properties; (ii) assess the mobility of metals and the degree of contamination within soil profiles; and (iii) investigate the relationship between soil properties and the chemical fractions of the heavy metals. Soil profiles located near a large copper smelter in the southwestern Poland were chosen for this study.

\section{MATERIALS AND METHODS \\ Description of the Study Area}

The Glogow copper smelters, located about $100 \mathrm{~km}$ northwest of Wroclaw (southwest Poland), belong to an industrial complex of copper mining and metallurgy. The complex was established in 1959 and involves four mines, three ore-dressing plants, and three smelters (Legnica, Glogow I, and Glogow II), and produces 400000 tons of $\mathrm{Cu}$ yearly (Dobrzanski and Byrdziak, 1995).

The Glogow I and II smelters are situated near the Odra river. The area is characterized by significant soil variations. The silty Alfisols and Inceptisols on sand dominate in the southern part of the studied area, whereas the northern part (the Odra Valley) is dominated by Entisols and Inceptisols developed from different alluvial deposits.

Strongly contaminated soils in the vicinity of smelters have been generally excluded from agricultural cultivation, as a socalled sanitary zone. The zone around the Glogow I and II smelters is 2840 ha and mostly afforested with black poplar (Populus nigra L.) and Canadian poplar [Populus x canadensis Moench var. serotina (Hartig)].

\section{Sampling Sites}

Four soil profiles were selected in the surroundings of copper smelters on soils differing in texture and level of contamination. The contamination is connected with location of the profiles, since the rate of soil pollution strongly depends on direction and distance to the smelters (Roszyk and Szerszen, 1988; Szerszen et al., 1993). Profiles 1 and 3 represent heavily contaminated soils, while 2 and 4 are relatively less polluted (Fig. 1). Profiles 1 and 2 were classified as a Hapludalf derived from silts. Profile 3 was classified as a Quartzipsamment derived from sandy deposits on loam, and Profile 4 as an Eutrudept derived from clay-loamy material on sand. Profiles 1, 3, and 4 were located under poplar forest, while Profile 2 was on cultivated land. Soils were described according to the Soil Survey Staff (1998). For all profiles, soil samples were collected from four different depths down to a maximum depth of 100 to $120 \mathrm{~cm}$.

\section{Soil Properties}

All soil samples were air-dried and ground to pass through a 2-mm sieve. Particle size distribution was determined by the hydrometer method for silt and clay, and by dry-sieving for sand fractions (Reeuwijk, 1995). Soil pH was measured in a $1: 2.5(\mathrm{v} / \mathrm{v})$ ratio of soil and water suspension (Reeuwijk, 1995). Organic carbon content was measured using a LECO (St. Joseph, MI) EC-12 carbon analyzer, after washing soil samples with $2 \mathrm{M} \mathrm{HCl}$. Total soil carbon was determined by LECO $\mathrm{CHN}-1000$ analyzer. The carbonate carbon was calculated as a difference between total and organic carbon. "Free" iron was analyzed by the citrate-bicarbonate-dithionite (CBD) method (Jackson et al., 1986). Cation exchange capacity was

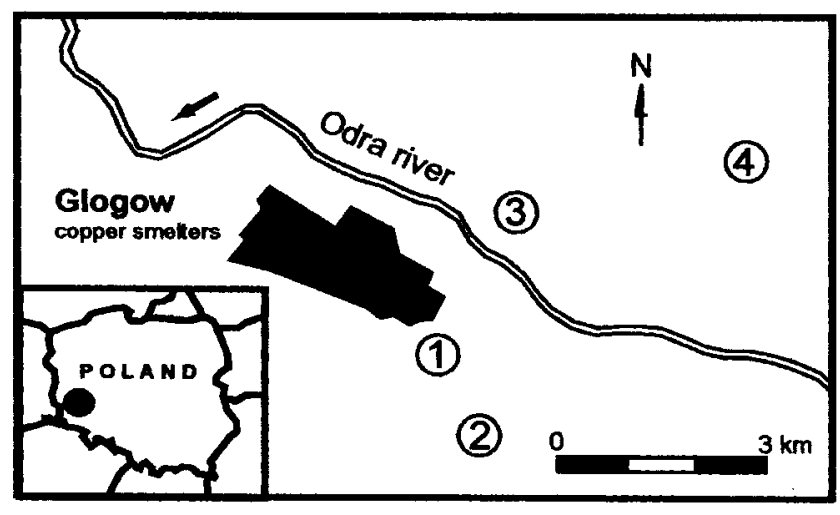

Fig. 1. Location of the study area and the soil profiles. 
determined as a sum of basic cations extracted with neutral $1 \mathrm{M} \mathrm{NH}_{4} \mathrm{OAc}$ and the extractable acidity (Reeuwijk, 1995). Calcium, magnesium, potassium, and sodium were determined by atomic absorption spectrophotometry or flame emission spectrometry, and soil acidity by back titration with $0.1 \mathrm{M}$ $\mathrm{NaOH}$.

\section{Trace Metal Fractionation}

The procedure of Salbu et al. (1998), which is a modified version of Tessier et al. (1979), was selected for this study. It is designed to separate heavy metals into six operationally defined fractions: reversibly physically sorbed as (F1) water extractable (water-soluble metals); (F2) extractable with $1 M$ $\mathrm{NH}_{4} \mathrm{OAc}$ at $\mathrm{pH} 7$ (exchangeable); (F3) extractable with $1 M$ $\mathrm{NH}_{4} \mathrm{OAc}$ at $\mathrm{pH} 5$ (specifically sorbed and carbonate bound); (F4) extractable with hydroxylamine (metals associated [sorbed or occluded] mainly on iron and manganese oxides); (F5) extractable with $\mathrm{H}_{2} \mathrm{O}_{2}$ in $1 M \mathrm{HNO}_{3}$ (strongly complexed by organic matter); and (F6) residual (extracted with $7 M$ $\mathrm{HNO}_{3}$ ).

Two grams of soil were weighed and placed in a $50-\mathrm{mL}$ polycarbonate centrifuge tube. The following extractions were made sequentially (Salbu et al., 1998).

(F1) Sample extracted with $20 \mathrm{~mL}$ of deionized water for $1 \mathrm{~h}\left(20^{\circ} \mathrm{C}\right.$, on rolling table).

(F2) The residue from (F1) extracted with $20 \mathrm{~mL}$ of $1 M$ $\mathrm{NH}_{4} \mathrm{OAc}, \mathrm{pH} 7$ for $2 \mathrm{~h}$.

(F3) The residue from (F2) extracted with $20 \mathrm{~mL}$ of $1 M$ $\mathrm{NH}_{4} \mathrm{OAc}, \mathrm{pH} 5$ for $2 \mathrm{~h}$.

(F4) The residue from (F3) extracted with $20 \mathrm{~mL}$ of $0.04 M$ $\mathrm{NH}_{2} \mathrm{OH} \cdot \mathrm{HCl}$ in $25 \% \mathrm{HOAc}$ for $6 \mathrm{~h}$ (water bath, $60^{\circ} \mathrm{C}$ ).

(F5) The residue from (F4) extracted with $15 \mathrm{~mL}$ of $30 \%$ $\mathrm{H}_{2} \mathrm{O}_{2}$ at $\mathrm{pH} 2$ (adjusted with $\mathrm{HNO}_{3}$ ) for $5.5 \mathrm{~h}$ (water bath, $80^{\circ} \mathrm{C}$ ). After cooling, $5 \mathrm{~mL}$ of $3.2 \mathrm{M} \mathrm{NH}_{4} \mathrm{OAc}$ in $20 \% \mathrm{HNO}_{3}$ was added, sample was shaken for $30 \mathrm{~min}$, and finally diluted to $20 \mathrm{~mL}$ with water.

(F6) One gram of the residue from (F5), after drying, was digested in a conical flask with $10 \mathrm{~mL}$ of $7 M \mathrm{HNO}_{3}$ on a hot plate for $6 \mathrm{~h}$. After evaporation, $1 \mathrm{~mL}$ of $2 M \mathrm{HNO}_{3}$ was added, and the residue after dissolution was diluted to $10 \mathrm{~mL}$.

All the solid phases (with exception of F6) were washed with $10 \mathrm{~mL}$ of water before the next extraction step. The washes were collected and analyzed with supernatant from the previous fraction. After each extraction, supernatant was separated by high-speed centrifugation for $30 \mathrm{~min}$ at $10000 \times$ $g$. To verify the sum of sequential extractions, the total concentration of $\mathrm{Cu}, \mathrm{Pb}$, and $\mathrm{Zn}$ was determined after digestion with aqua regia.

In order to assess the mobile and potentially bioavailable fractions, a single extraction of heavy metals was carried out with $0.01 M \mathrm{CaCl}_{2}$ in a 1:10 (w/v) ratio of soil and extractant. This extractant has been proposed to simulate soil solution concentration and to release amounts of metals that are well correlated with plant uptake (Iyengar et al., 1981; Karczewska et al., 1998). Two grams of soil were extracted with $20 \mathrm{~mL}$ of $0.01 \mathrm{M} \mathrm{CaCl}_{2}$ by shaking for $2 \mathrm{~h}$ at $20^{\circ} \mathrm{C}$. The rest of the procedure was the same as described earlier for sequential extraction. Concentrations of $\mathrm{Cu}, \mathrm{Pb}$, and $\mathrm{Zn}$ in every extract were measured by flame atomic absorption spectrophotometry.

\section{RESULTS AND DISCUSSION}

\section{Soil Properties}

The most important difference in the profiles studied is their clay content. Profiles 1 and 2 are silty (silt loam) soils with an illuvial increase of clay content with depth. Profile 3 is a deep sandy soil poor in clay (1-4\%) and underlain by clay loam ( $28 \%$ clay). Profile 4 represents clay-loam soil on loamy sand developed from alluvial deposits (Table 1). Soil pH in all profiles was rather high, caused by intensive liming in the vicinity of copper smelter. Organic carbon content in all profiles was generally $<1 \%$, reaching, however, 1.5 and $2.2 \%$ in surface horizons of Profiles 2 and 4, respectively. Cation exchange capacity varied from 2 to $77 \mathrm{cmol}_{\mathrm{c}} \mathrm{kg}^{-1}$ of soil and it correlated significantly $(P<0.05)$ with clay, organic carbon, and Fe-Mn oxides contents. The content of "free" iron (dithionite-extractable) was considerably higher in clay-rich horizons, and particularly the high amount in Profile 4 was associated with the presence of iron concretions.

\section{Total Concentration of Heavy Metals}

Total concentrations of heavy metals in the studied profiles reflect both natural differences in soil genesis

Table 1. Location of the profiles and basic physicochemical properties of studied soils.

\begin{tabular}{|c|c|c|c|c|c|c|c|c|}
\hline $\begin{array}{l}\text { Profile location and } \\
\text { distance to smelter }\end{array}$ & Depth & Clay & Silt & $\underset{\left(\mathbf{H}_{2} \mathbf{O}\right)}{\mathbf{p H}}$ & $\mathrm{OC}^{\dagger}$ & $\mathrm{CaCO}_{3}$ & $\mathbf{F e}_{\mathrm{d}}+$ & CEC§ \\
\hline & cm & \multicolumn{2}{|c|}{$\%$} & & \multicolumn{3}{|c|}{ \% } & $\operatorname{cmol}_{\mathrm{c}} \mathbf{k g}^{-1}$ \\
\hline 1 & 0-18 & 8 & 58 & 5.96 & 0.97 & 0 & 0.42 & 7.04 \\
\hline Zukowice & $18-45$ & 7 & 62 & 5.36 & 0.44 & 0 & 0.36 & 5.77 \\
\hline \multirow[t]{2}{*}{$1.0 \mathrm{~km} \mathrm{SE}$} & $45-60$ & 8 & 56 & 5.86 & 0.37 & 0 & 0.37 & 6.82 \\
\hline & $60+$ & 19 & 51 & 6.60 & 0.19 & $\mathbf{0}$ & 0.63 & 9.89 \\
\hline 2 & 0-20 & 10 & 52 & 6.31 & 1.48 & $\mathbf{0}$ & 0.49 & 9.86 \\
\hline Biechow & $20-45$ & 12 & 52 & 7.07 & 0.34 & 0 & 0.52 & 9.88 \\
\hline \multirow[t]{2}{*}{$2.5 \mathrm{~km} \mathrm{SE}$} & $45-65$ & 27 & 57 & 7.39 & 0.27 & 0.3 & 0.87 & 17.16 \\
\hline & $65+$ & 24 & 51 & 8.12 & 0.16 & 0.7 & 1.07 & 21.66 \\
\hline 3 & 0-18 & $\mathbf{1}$ & 4 & 7.63 & 0.39 & 0.5 & 0.22 & 4.00 \\
\hline Bogomice & $18-40$ & 4 & 4 & 7.19 & 0.13 & 0 & 0.29 & 3.59 \\
\hline \multirow[t]{2}{*}{$2.5 \mathrm{~km} \mathrm{NE}$} & $40-100$ & 1 & 2 & 6.91 & 0.09 & 0 & 0.20 & 2.02 \\
\hline & $100+$ & 28 & 44 & 5.92 & 0.55 & 0 & 1.77 & 22.86 \\
\hline 4 & 0-27 & 29 & 31 & 7.68 & 2.18 & 0.5 & 5.17 & 73.54 \\
\hline Zabiele & $27-45$ & 34 & 23 & 7.28 & 0.9 & 0 & 9.57 & 77.33 \\
\hline \multirow[t]{2}{*}{$6.0 \mathrm{~km} \mathrm{NE}$} & $45-100$ & 34 & 15 & 7.24 & 0.49 & 0 & 20.47 & 41.61 \\
\hline & $100+$ & 12 & 2 & 6.82 & 0.18 & 0 & 2.20 & 14.42 \\
\hline
\end{tabular}

$\dagger$ Organic carbon.

+ Citrate-dithionite extractable iron.

$\S$ Cation exchange capacity (sum of basic cations and soil extractable acidity). 
Table 2. Total contents of $\mathrm{Cu}, \mathrm{Pb}$, and $\mathrm{Zn}$ and the sum of fractions obtained by sequential extraction.

\begin{tabular}{|c|c|c|c|c|c|c|c|}
\hline \multirow{2}{*}{$\begin{array}{l}\text { Profile } \\
\text { location }\end{array}$} & \multirow[b]{2}{*}{ Depth } & \multicolumn{3}{|c|}{ Total content $\dagger$} & \multicolumn{3}{|c|}{$\begin{array}{c}\text { Sum of fractions } \\
\text { F1 to F6 }\end{array}$} \\
\hline & & Cu & $\mathbf{P b}$ & $\mathbf{Z n}$ & $\mathbf{C u}$ & $\mathbf{P b}$ & $\mathbf{Z n}$ \\
\hline & cm & \multicolumn{6}{|c|}{$\mathrm{mg} \mathrm{kg}^{-}$} \\
\hline $\mathbf{1}$ & $0-18$ & 369 & 118 & 46.8 & 361 & 112 & 50.6 \\
\hline \multirow[t]{3}{*}{ Zukowice } & $18-45$ & 8.1 & 9.4 & 41 & 8.0 & 10.0 & 8.2 \\
\hline & $45-60$ & 6.1 & 8.0 & 20 & 6. & 8.7 & 17. \\
\hline & $60+$ & 8.2 & 10.4 & 29.3 & 7.0 & 9.4 & 26. \\
\hline 2 & 0-20 & 96.9 & 83.8 & 51.0 & 89.0 & 80.1 & 50.7 \\
\hline \multirow[t]{3}{*}{ Biechow } & 20 & 8.3 & 15 & 21 & 8.1 & 1 & 21 \\
\hline & 45 & 10.7 & 12 & 34 & 10.6 & 1. & 37 \\
\hline & $65+$ & 12. & 12.4 & 34.8 & 10.2 & 13.3 & 38.8 \\
\hline \multirow{4}{*}{ Bogomice } & $0-18$ & 426 & 130 & 44.8 & 394 & 122 & 54.5 \\
\hline & $18-4$ & 7.3 & 6.3 & 11.8 & 6.4 & 7.2 & 14. \\
\hline & 40- & 3.7 & 4 & 8 & 4.0 & 3.9 & \\
\hline & $100+$ & 17.0 & 18.0 & $\mathbf{7 3 . 3}$ & 14.6 & 20.0 & 78.2 \\
\hline & $0-2$ & 115 & 65.0 & 92.3 & 117 & 68.1 & 99.6 \\
\hline \multirow{3}{*}{ Zabiele } & 27- & 28.3 & 35.5 & 80. & 27.8 & 40.0 & \\
\hline & 45- & 17. & 32 & 50 & 16.5 & 33.5 & 50.8 \\
\hline & $100+$ & 5.6 & 15.0 & 17.9 & 4.8 & 14.8 & 17.4 \\
\hline
\end{tabular}

$\dagger$ Aqua regia-soluble.

and properties and the degree of contamination (Table 2 ). The total content of $\mathrm{Cu}$ in the surface horizons ranged from 97 to $426 \mathrm{mg} \mathrm{kg}^{-1}$, while in the subsurface horizons $\mathrm{Cu}$ concentrations were much lower, ranging from 3.7 to $28.3 \mathrm{mg} \mathrm{kg}^{-1}$. The concentration ratio (total $\mathrm{Cu}$ in surface layer versus $\mathrm{Cu}$ in parent material) depends on the distance to the copper smelter and direction of dominating wind. In the soils located ca. $6 \mathrm{~km}$ northeast of the factory and $2.5 \mathrm{~km}$ southeast, the ratios were 7 and 8 , respectively, while in the heavily polluted silty soil (1 km southeast) and sandy soil $(2.5 \mathrm{~km}$ northeast) the ratios were as high as 45 and 115 , respectively. The corresponding ratios for $\mathrm{Pb}$ were 2 and 30, again depending on distance to the smelter, direction, and soil texture. The concentrations of $\mathrm{Cu}$ and $\mathrm{Pb}$ found in these soils were significantly higher than typical values in agricultural soils (Kabata-Pendias and Pendias, 1992) but they were distinctly lower than those previously reported by Roszyk and Szerszen (1988) and Szerszen et al. (1993) in the vicinity of copper smelter in Poland. Although the content of $\mathrm{Zn}\left(8.2-92.3 \mathrm{mg} \mathrm{kg}^{-1}\right)$ was in the typical range (Kabata-Pendias and Pendias, 1992), significantly higher amounts in the surface horizons may have resulted both from bioaccumulation and the airborne pollution. The highest concentration ratio of $\mathrm{Zn}$ (ca. 6) was found in the sandy soil (Profile 3).

No significant correlations between soil properties and the total concentrations of $\mathrm{Cu}$ and $\mathrm{Pb}$ were found. However, Zn correlated significantly and positively with clay and organic carbon contents, cation exchange capacity, and iron oxides (Table 4), which suggests less soil contamination with this metal.

\section{Fractionation and Distribution of Metals in Soil Profiles}

\section{Copper}

The main difference in the distribution of $\mathrm{Cu}$ in soil profiles was in the relative contribution of residual and nonresidual fractions (Fig. 2). In the surface horizons of polluted soils, the contribution of the residual fraction did not exceed $7 \%$ of the total $\mathrm{Cu}$. However, the subsurface horizons of less contaminated soils were dominated by the stabile fraction strongly bound to soil components (F6). Up to 88 and $97 \%$ of total copper in the silty (Profiles 1 and 2) and the clay-loamy soils (Profile 4), respectively, were present in this fraction. The sandy soil (Profile 3) was a special case, with a low percentage of metals in the residual fraction both in the surface and subsurface horizons. This is probably a result of the low clay content and negligible sorption by dominant quartz grains.

A special feature of the surface horizons of the contaminated soils was a particularly high amount of copper extracted with $1 \mathrm{M} \mathrm{NH}_{4} \mathrm{OAc}$ (F2 and F3). Depending on the $\mathrm{pH}$ of extraction used $(\mathrm{pH} 7.0$ or 5.0), this fraction includes $\mathrm{Cu}$ held by electrostatic adsorption (exchangeable) and that specifically adsorbed (Christensen and Huang, 1999). The metals found in these fractions may become available to plants upon solubilization. Up to $62 \%$ of the total $\mathrm{Cu}$ in the surface horizons of the sandy soil (Profile 3 ) and up to $45 \%$ in the silty soils (Profiles 1 and 2) was present in these two fractions (F2 and F3). Such high percentages of exchangeable and specifically adsorbed $\mathrm{Cu}$ in contaminated soils in the vicinity of a
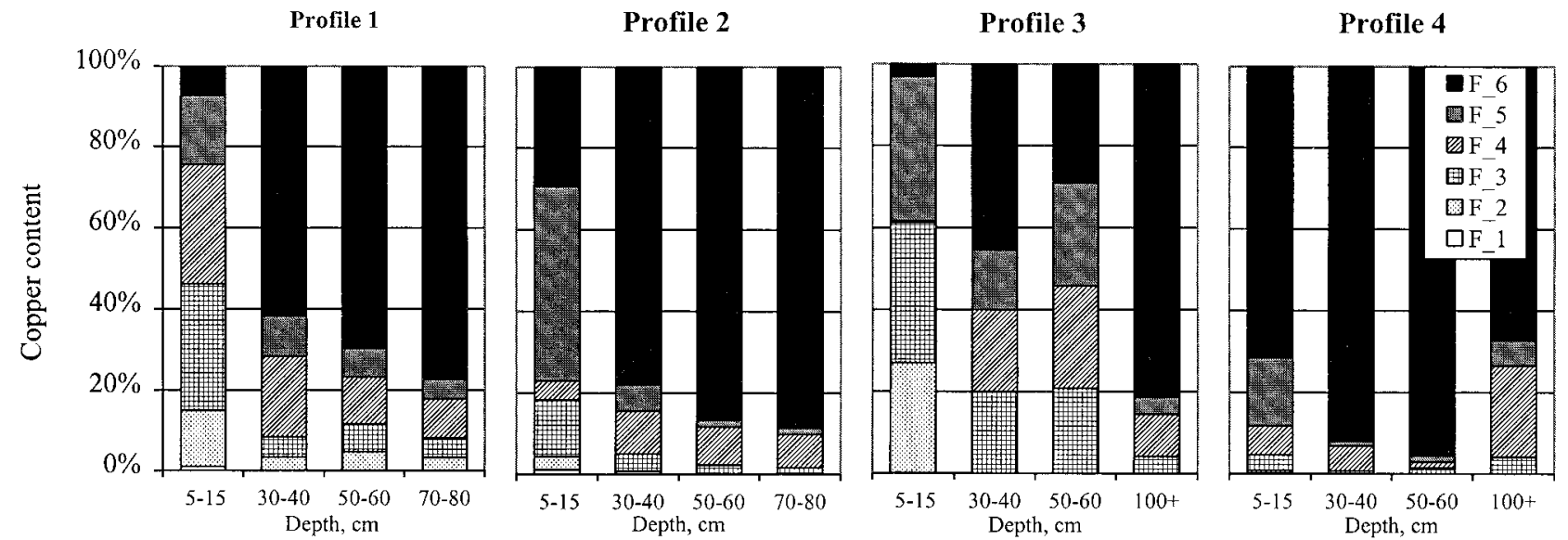

Fig. 2. Distribution of the copper fractions in different soil profiles. Extractants: F-1, $\mathrm{H}_{2} \mathrm{O} ; \mathrm{F}-2,1 \mathrm{M} \mathrm{NH}_{4} \mathrm{OAc}(\mathrm{pH}$ 7.0); F-3, $1 \mathrm{M}$ NH 4 OAc (pH 5.0); F-4, $1 M \mathrm{NH}_{2} \mathrm{OH} . \mathrm{HCl}$ in $25 \% \mathrm{HOAc}$; $\mathrm{F}-5,30 \% \mathrm{H}_{2} \mathrm{O}_{2}$ in $\mathrm{HNO}_{3}$ (pH 2.0); F-6, aqua regia. 
copper smelter were also reported by Karczewska (1996). The fraction extracted at pH 5.0 (F3) was twoto sixfold higher than that extracted at $\mathrm{pH} 7.0(\mathrm{~F} 2)$ in all soils. The relative contribution of the exchangeable copper fraction (F2) decreased significantly with depths within each profile. Despite the high total content of copper in some soils $\left(>400 \mathrm{mg} \mathrm{kg}^{-1}\right)$, the water-soluble fraction (F1) was negligible in most of the soils. This can be considered a symptom of low lability of copper in these profiles.

Less contaminated surface horizons as well as subsurface horizons of all soils contained significant amounts of hydroxylamine-extracted $\mathrm{Cu}$ (F4), generally 20 to $30 \%$ of the total $\mathrm{Cu}$ in the surface and subsurface horizons, respectively. This fraction contained relatively low amounts of metals in the surface horizon of the contaminated sandy soil (Profile 3 ) and in subsurface horizons of Profile 4, which was enriched with iron oxides. Predominance of the exchangeable and specifically adsorbed copper fractions over the "reducible" fraction found in this study, as well as that of Karczewska (1996), seems to be a typical feature associated with the very high emissions of $\mathrm{Cu}$ from the smelters. The highest amount of organically complexed $\mathrm{Cu}$ was extracted from the contaminated sandy soil $\left(140 \mathrm{mg} \mathrm{kg}^{-1}\right)$, but the highest relative percentage of this element was found in the silty soil (Profile 2). With the exception of Profile 1, organically bound $\mathrm{Cu}$ was a dominant nonresidual single fraction in the surface horizons of both highly and less contaminated soils. Absolute concentrations, as well as the relative percentage of this fraction, decreased in the subsurface horizons of all profiles due to decreased organic matter content.

\section{Lead}

No detectable amounts of water-soluble $\mathrm{Pb}$ were extracted from the less-contaminated soils (Fig. 3), and even in the contaminated soils this fraction contained $<0.5 \mathrm{mg} \mathrm{kg}^{-1}$. However, the amounts of $\mathrm{Pb}$ extracted by $\mathrm{NH}_{4} \mathrm{OAc}(\mathrm{pH} 7.0)$ increased to about 8 and $14 \%$ of the total $\mathrm{Pb}$ in the less-contaminated and contaminated profiles, respectively. The amount of $\mathrm{Pb}$ extracted by $\mathrm{NH}_{4} \mathrm{OAc}$ ( $\mathrm{pH} 5.0$ ) was considerably higher (up to $45 \%$ of the total $\mathrm{Pb}$ in contaminated horizons). The percentage of $\mathrm{NH}_{4} \mathrm{OAc}$ ( $\mathrm{pH} 5.0$ ) extractable $\mathrm{Pb}$ was in the order: sandy $>$ silty $>$ clay-loam soils. The percentage of this fraction in the subsurface horizons of all soils, both contaminated and less contaminated, was rather small (less than $3 \%$ of total $\mathrm{Pb}$ content). The exchangeable and specifically adsorbed fractions $(\mathrm{F} 2+\mathrm{F} 3)$ were found to dominate only in the surface horizons of contaminated soils (up to $60 \%$ of total $\mathrm{Pb}$ ). In less-contaminated soils (horizons), both fine- and coarse-textured, exchangeable and specifically adsorbed $\mathrm{Pb}$ generally did not exceed $10 \%$ of total $\mathrm{Pb}$. These results are similar to those of Karczewska (1996), but the magnitude of the exchangeable and specifically adsorbed fraction in the present study $(60 \%)$ was higher than the values $(25 \%)$ reported by Karczewska. On the other hand, in soils polluted by lead smelters, Chlopecka et al. (1996) found only $6 \%$ of total $\mathrm{Pb}$ in the exchangeable fraction and $13 \%$ in the fraction extracted by acid $\mathrm{NH}_{4} \mathrm{OAc}$. Ramos et al. (1994) reported nondetectable amounts of exchangeable $\mathrm{Pb}$, but they found up to $45 \%$ of carbonate-bound $\mathrm{Pb}$ in the surface horizons of unpolluted soils.

Despite the reported affinity of $\mathrm{Pb}$ to soil organic matter (Kabata-Pendias and Pendias, 1992), the organically bound fraction (F5) was one of the smallest (or even negligible) in the surface horizons of all soils. The percentage of this fraction did not exceed 1, 3, and $8 \%$ of total $\mathrm{Pb}$ in the sandy, silty, and clay-loam soils, respectively. The dominant fraction of $\mathrm{Pb}$ in all soils was that extracted with $\mathrm{NH}_{2} \mathrm{OH} \cdot \mathrm{HCl}(\mathrm{F} 4)$. The percentages of this fraction, 53, 34, and $23 \%$ of total $\mathrm{Pb}$, were found in surface horizons of the silty, sandy, and clayloamy soils, respectively. The surprisingly low percentage of organically complexed $\mathrm{Pb}$, accompanied by a high contribution of the "reducible" fraction, was found even in the surface horizons. The dominance of an oxideoccluded fraction of $\mathrm{Pb}$, both in contaminated and lesscontaminated soils, has been reported by other investigators (Ramos et al., 1994; Karczewska, 1996; Ahumada et al., 1999). In soils polluted by lead smelting, the mean percentage of lead in the oxide-bound fraction was estimated to be $57 \%$, while organically complexed $\mathrm{Pb}$ accounted for only $14 \%$ of total $\mathrm{Pb}$ (Chlopecka et al.,
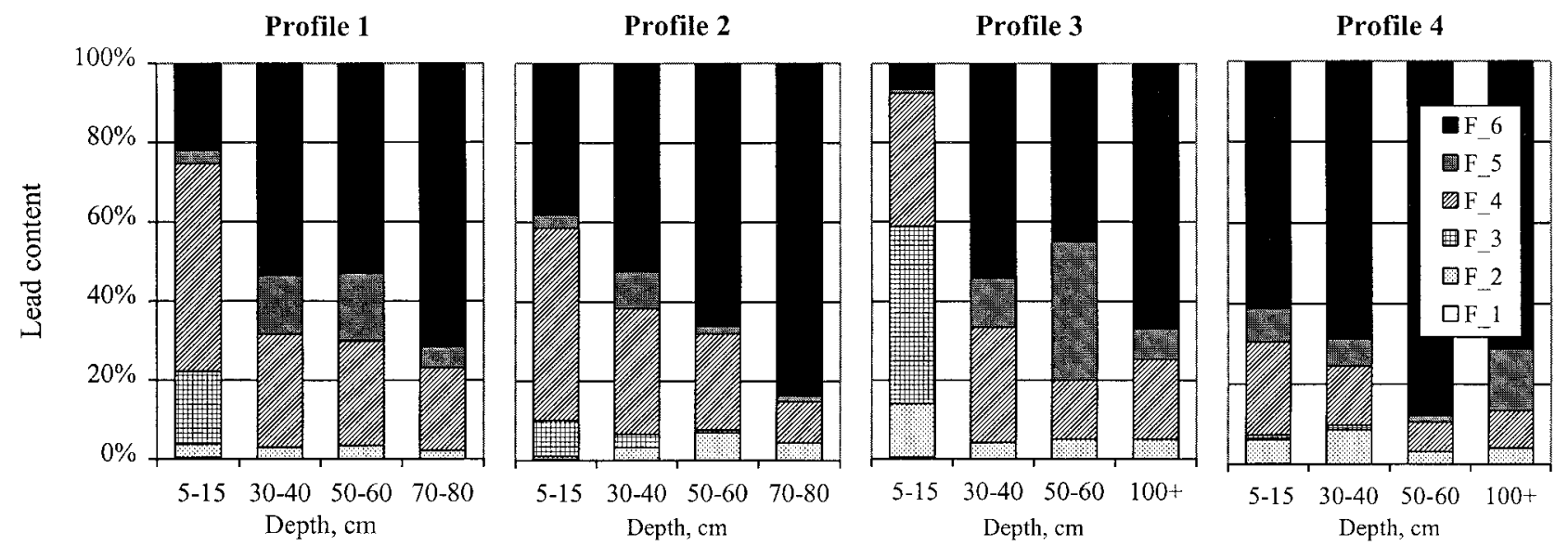

Fig. 3. Distribution of the lead fractions in different soil profiles. Extractants: F-1, $\mathrm{H}_{2} \mathrm{O} ; \mathrm{F}-2,1 \mathrm{M} \mathrm{NH}_{4} \mathrm{OAc}(\mathrm{pH} 7.0) ; \mathrm{F}-3,1 \mathrm{M} \mathrm{NH} \mathrm{N}_{4} \mathrm{OAc}(\mathrm{pH}$ 5.0); F-4, $1 \mathrm{M} \mathrm{NH} \mathrm{NH}_{2} \mathrm{OH} . \mathrm{HCl}$ in $25 \%$ HOAc; F-5, $30 \% \mathrm{H}_{2} \mathrm{O}_{2}$ in $\mathrm{HNO}_{3}$ (pH 2.0); F-6, aqua regia. 

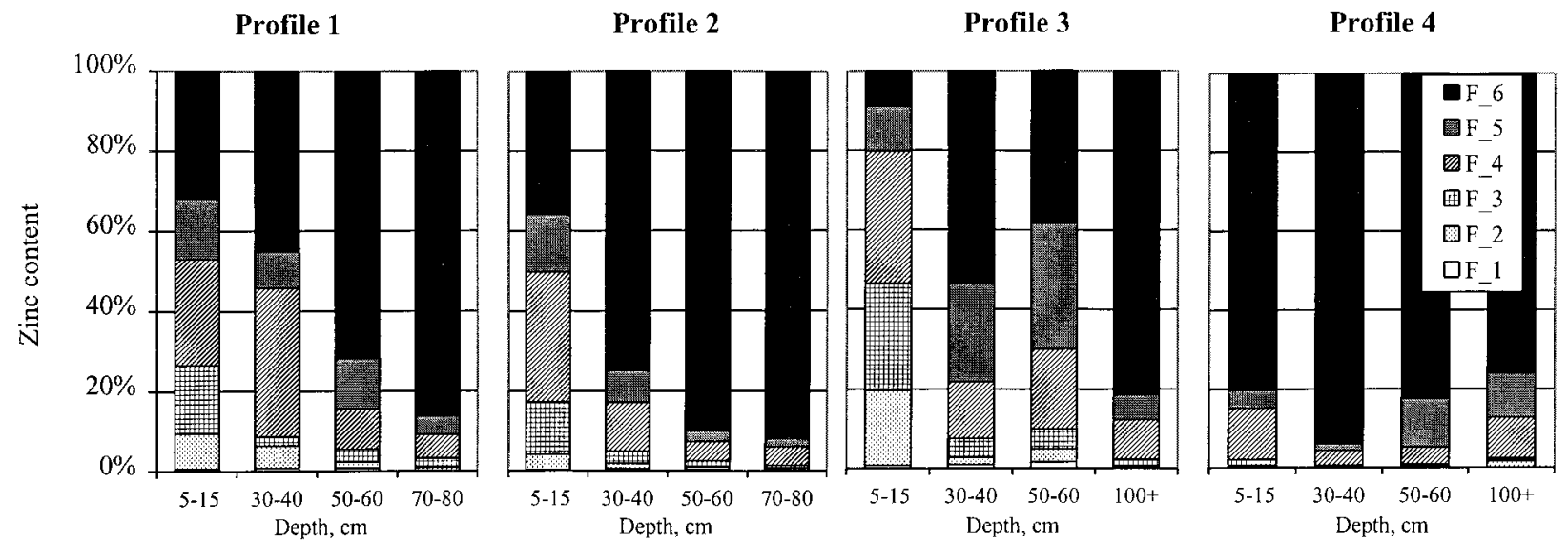

Fig. 4. Distribution of the zinc fractions in different soil profiles. Extractants: F-1, $\mathrm{H}_{2} \mathrm{O} ; \mathrm{F}-2,1 M \mathrm{NH}_{4} \mathrm{OAc}\left(\mathrm{pH}\right.$ 7.0); F-3, $1 M$ NH $\mathrm{NAc}_{4} \mathrm{OAH}$ 5.0); F-4, $1 M \mathrm{NH}_{2} \mathrm{OH} . \mathrm{HCl}$ in $25 \% \mathrm{HOAc}$; $\mathrm{F}-5,30 \% \mathrm{H}_{2} \mathrm{O}_{2}$ in $\mathrm{HNO}_{3}$ (pH 2.0); F-6, aqua regia.

1996). Like $\mathrm{Cu}$, the dominant fraction of $\mathrm{Pb}$ in lesscontaminated soils of this study was the residual fraction (84-88\% of the total $\mathrm{Pb}$ ), particularly in the subsurface horizons of the fine-textured soils.

\section{Zinc}

The water-soluble $\mathrm{Zn}$ was present in very small amounts $(<1 \%)$ in most of the soils (Fig. 4). Zinc extracted with $\mathrm{NH}_{4} \mathrm{OAc}(\mathrm{pH}$ 7.0) in the subsurface horizons was also low $\left(0.2-1.5 \mathrm{mg} \mathrm{kg}^{-1}\right.$, equivalent to $0.3-$ $5.6 \%$ of total $\mathrm{Zn}$ ). The concentration of exchangeable Zn was significantly higher in surface horizons (4-19\% of total $\mathrm{Zn}$ ) than in subsurface layers. The dominant fraction among the weakly bound fractions was that extracted with $\mathrm{NH}_{4} \mathrm{OAc}$ at $\mathrm{pH}$ 5.0. This fraction accounted for 1.8 to $27 \%$ of total $\mathrm{Zn}$ in the surface horizons and 0.2 to $5.4 \%$ in the subsurface ones (Fig. 4). The sum of weakly bound fractions of $\mathrm{Zn}(\mathrm{F} 1+\mathrm{F} 2+\mathrm{F} 3)$ was highest in surface horizons of the strongly polluted sandy soils ( $45 \%$ of total $\mathrm{Zn}$ ). The corresponding values of these fractions in the silty and clay-loam soils were 18 to $26 \%$ and $2 \%$, respectively. Subsurface horizons of all soils contained considerably lower amounts of these $\mathrm{Zn}$ fractions ( $<8 \%$ of the total $\mathrm{Zn}$ ).

In subsurface horizons of the studied soils, $\mathrm{Zn}$ was concentrated in the residual fraction (F6). The percentage of residual $\mathrm{Zn}$ ranged between $45 \%$ in silty soils to $94 \%$ in the clay-loam soil. The nonresidual fractions prevailed only in the surface horizons, both in the contaminated and the less contaminated soils (65-91\% of total Zn). Ma and Rao (1997) and Narwal et al. (1999) also found $\mathrm{Zn}$ to be strongly bound in the residual fraction (even up to $98 \%$ of its total content). Among the nonresidual forms, the oxide-bound and to a lesser extent organically complexed fractions occurred in the highest percentage. The percentage of $\mathrm{NH}_{2} \mathrm{OH} \cdot \mathrm{HCl}-$ extractable $\mathrm{Zn}(\mathrm{F} 4)$ in surface horizons ranged from $13 \%$ in the clay-loam soil to $33 \%$ in the silty and sandy soils. The contribution of this fraction decreased with the depth in all of the soil profiles. In agreement with these results, other investigators also reported the dominance of the $\mathrm{Fe}$ and $\mathrm{Mn}$ oxide-bound $\mathrm{Zn}$ (Shuman,
1985; Ramos et al., 1994; Karczewska, 1996; Narwal et al., 1999; Ahumada et al., 1999).

On the basis of results obtained in this study, the relative significance of $\mathrm{Cu}, \mathrm{Pb}$, and $\mathrm{Zn}$ fractions in subsurface horizons of the fine-textured less-contaminated soils was in the order: residual $>>\mathrm{Fe}-\mathrm{Mn}$ oxides occluded $>$ organically complexed $>$ exchangeable and specifically adsorbed. The order of fractions in the subsurface sandy horizons was: residual $>$ organically complexed $>\mathrm{Fe}-\mathrm{Mn}$ oxides occluded $>$ exchangeable and specifically adsorbed. It is difficult if not impossible to establish one scheme of fraction order in the surface horizons, universal for all metals and different soils. There were, however, characteristic features of these horizons: low percentages of metals in the residual fraction and predominance of the oxide-bound fraction in the less contaminated soils, and dominance of the $\mathrm{NH}_{4} \mathrm{OAc}$-extractable fraction in the highly contaminated soils. The organically complexed fraction dominated only for $\mathrm{Cu}$.

\section{Mobility of Copper, Lead, and Zinc in Soil Profiles}

The mobility of metals in soil profiles may be assessed on the basis of absolute and relative content of fractions weakly bound to soil components. The relative index of metal mobility was calculated as a "mobility factor" (MF; Salbu et al., 1998; Narwal et al., 1999) on the basis of the following equation:

$$
\mathrm{MF}=\frac{(\mathrm{F} 1+\mathrm{F} 2+\mathrm{F} 3)}{(\mathrm{F} 1+\mathrm{F} 2+\mathrm{F} 3+\mathrm{F} 4+\mathrm{F} 5+\mathrm{F} 6)} \times 100
$$

Since some metal forms (extracted in F3) are relatively less mobile (more strongly bound to the soil components than those extracted in F1 and F2), the above mentioned index describes the potential mobility (Salbu et al., 1998). The MF gave values not higher than $10 \%$ (for all metals) in subsurface horizons, which is a symptom of high stability of heavy metals in these horizons, even if surface layers contained high metal concentrations. Only the MF for $\mathrm{Cu}$ in subsurface horizons of the strongly contaminated sandy soil reached $20 \%$. The 
Table 3. Water, $0.01 M \mathrm{CaCl}_{2}$, and $1 M \mathrm{NH}_{4} \mathrm{OAc}$ extractable fractions of $\mathrm{Cu}, \mathrm{Pb}$, and $\mathrm{Zn}$ (mean values) in studied soils.

\begin{tabular}{|c|c|c|c|c|}
\hline \multirow[b]{2}{*}{ Element } & \multicolumn{4}{|c|}{ Fractions extracted with: } \\
\hline & $\mathrm{H}_{2} \mathrm{O}$ & $\begin{array}{c}0.01 M \\
\mathrm{CaCl}_{2}\end{array}$ & $\underset{\text { pH } 7.0 \dagger}{1 \mathrm{MH} \mathrm{NH}_{4} \mathrm{OAc}}$ & $\begin{array}{c}1 M \mathrm{NH}_{4} \mathrm{OAc} \\
\text { pH } 7.0 \text { and } 5.0 \%\end{array}$ \\
\hline & & & $\mathbf{m g ~ k g}^{-1}$ & \\
\hline $\mathbf{C u}$ & 0.31 & 0.63 & 8.94 & 10.25 \\
\hline $\mathbf{P b}$ & 0.08 & 0.29 & 2.06 & 6.81 \\
\hline $\mathbf{Z n}$ & 0.08 & 0.44 & 0.30 & 2.71 \\
\hline
\end{tabular}

$\dagger$ Fraction $\mathbf{F} 2$ of sequential extraction.

$\$$ Sum of fractions $F 2$ and $F 3$ of sequential extraction.

indices of mobility were considerably higher (particularly for $\mathrm{Cu}$ ) in the surface horizons of the soils located close to the smelters. The $\mathrm{MF}_{\mathrm{Cu}}$ increased to 46 and $61 \%$ in the silty and sandy soils, respectively. The corresponding indexes for $\mathrm{Pb}$ were 22 and $59 \%$ and for $\mathrm{Zn} 26$ and $46 \%$. The high MF values have been interpreted as symptoms of relatively high lability and biological availability of heavy metals in soils (Karczewska, 1996; Ma and Rao, 1997; Ahumada et al., 1999; Narwal et al., 1999).

The results of a single extraction with $0.01 \mathrm{M} \mathrm{CaCl}_{2}$, imitating a soil solution concentration, showed significantly higher amounts of labile metals than that released with water (Table 3 ), but the amounts were considerably lower than those extracted with $\mathrm{NH}_{4} \mathrm{OAc}$, both at $\mathrm{pH}$ 7.0 and 5.0. Calcium chloride solution released only about 6,4 , and $16 \%$ of $\mathrm{Cu}, \mathrm{Pb}$, and $\mathrm{Zn}$ "mobile" fractions $(\mathrm{F} 1+\mathrm{F} 2+\mathrm{F} 3)$, respectively. The amounts of metals extracted with $\mathrm{NH}_{4} \mathrm{OAc}$ (at different $\mathrm{pH}$ ) have been reported to correlate with plant uptake (Iyengar et al., 1981; Shuman, 1990; Ahumada et al., 1999) and are used as indicators of potential bioavailability. Change in $\mathrm{pH}$, organic matter content, and redox status of the contaminated soils may alter bioavailability of the weakly bound heavy metals (Iyengar et al., 1981; He and Singh, 1993; Karczewska et al., 1998; Narwal and Singh, 1998).

The results of this study show that metal mobility, estimated on the basis of exchangeable fractions in surface horizons, does not determine the redistribution of heavy metals to deeper horizons. Kuo et al. (1983) and Szerszen et al. (1993) made similar conclusions, emphasizing the predominance of heavy metal accumulation in surface horizons of the highly contaminated soils and the lack of their redistribution in the soil profile.

The relationship between soil properties and the results of sequential extraction was investigated, but in the presence of highly variable soil properties and with the distance from copper smelters as a factor influencing the degree of contamination, most relationships were not statistically significant (and hence are not presented). Mobility indexes were, however, significantly correlated with clay content and with the total content of metals, with minor exceptions (Table 4). Strongly positive correlations with total $\mathrm{Cu}$ and $\mathrm{Pb}$ content indicates overloading of the geochemical system in the contaminated soils, where anthropogenically added metals remained weakly bound to soil constituents (Ramos et al., 1994). Lack of significant correlation between mobility indexes of $\mathrm{Zn}$ and its total content suggests lower $\mathrm{Zn}$ contamina-
Table 4. Coefficients of determination between total metal content and mobility factors, and selected physicochemical properties of soils.

\begin{tabular}{|c|c|c|c|c|c|c|}
\hline Factor & Clay & pH & $\mathbf{O C}^{\mathrm{c}}$ & $\mathbf{F e}_{\mathbf{d}}^{c}$ & $\mathrm{CEC} \dagger$ & $\mathbf{T M} \div$ \\
\hline & -0.33 & $\mathbf{0}$ & 0.2 & -0.1 & 0.12 & - \\
\hline & -0.19 & 0.06 & & 0.01 & 0.05 & - \\
\hline & $0.65 * *$ & 0.10 & $0.77 *$ & 0.40 & $0.79 *$ & - \\
\hline $\mathbf{I F}_{\mathrm{Cu}} \S$ & $-0.65 * *$ & -0.05 & $-\mathbf{0 . 0 3}$ & $-\mathbf{0 . 3 3}$ & -0.42 & $0.91 * * *$ \\
\hline $\mathbf{I F}_{\mathbf{P b}}$ & -0.4 & 0.21 & $-\mathbf{0 . 0 1}$ & -0.16 & -0 & $1 * *$ \\
\hline & $-0.59 * *$ & -0.04 & 0.09 & -0.30 & -0.39 & 0.20 \\
\hline \multicolumn{7}{|c|}{$\begin{array}{l}* \text { Significant at the } 0.05 \text { probability level. } \\
* * \text { Significant at the } 0.01 \text { probability level. } \\
* * * \text { Significant at the } 0.001 \text { probability level. } \\
+ \text { Cation exchange capacity. } \\
+ \text { Total content of metal. } \\
\$ \text { MF = mobility factor: proportion of mobile }(\mathbf{F 1}+\mathbf{F} 2+\text { F3) to total } \\
\text { sum of fractions. }\end{array}$} \\
\hline
\end{tabular}

tion with this metal and a strong relation to soil properties.

\section{CONCLUSIONS}

The heavy metal contamination was primarily restricted to surface horizons, but there was potential mobility of metals in the highly contaminated profiles. Distributions of heavy metals among chemical fractions were generally dependent on the total content of metals and soil texture. The residual fraction dominated in the less-contaminated surface and subsurface horizons. Common features of the surface horizons were low percentage of the residual fraction and the dominance of the oxide-bound fraction in less-contaminated soils and the $\mathrm{NH}_{4} \mathrm{OAc}$-extractable fraction in the highly polluted soils.

The mobile metal fractions increased to more than $50 \%$ of the total metal contents in the surface horizons of highly contaminated profiles, but the amounts of $\mathrm{Cu}$, $\mathrm{Pb}$, and $\mathrm{Zn}$ extracted with $0.01 \mathrm{M} \mathrm{CaCl}_{2}$ accounted for only a small $(<16 \%)$ part of that extracted with $\mathrm{NH}_{4} \mathrm{OAc}$. This confirms the rather low content of the most labile forms of heavy metals in these soils.

The mobility indexes of $\mathrm{Cu}$ and $\mathrm{Pb}$ correlated strongly and positively with their total content, indicating that the anthropogenically added metals remained in relatively weakly bound forms. The relative mobility of metals in the contaminated soils was increased by an increase in their total content and decreased by increasing content of clay in the soil.

\section{ACKNOWLEDGMENTS}

The first author is grateful to the Research Council of Norway for granting a fellowship, and to the staff of the Department of Soil and Water Sciences, Agricultural University of Norway, for their kind help as well as technical and financial assistance in conducting this research. The authors acknowledge Prof. Leszek Szerszen, Institute of Soil Science, Agricultural University of Wroclaw, for his assistance during the selection and sampling of soil profiles in Poland.

\section{REFERENCES}

Ahnstrom, Z.S., and D.R. Parker. 1999. Development and assessment of a sequential extraction procedure for the fractionation of soil cadmium. Soil Sci. Soc. Am. J. 63:1650-1658. 
Ahumada, I., J. Mendoza, and L. Ascar. 1999. Sequential extraction of heavy metals in soils irrigated with wastewater. Commun. Soil Sci. Plant Anal. 30:1507-1519.

Chlopecka, A., J.R. Bacon, M.J. Wilson, and J. Kay. 1996. Forms of cadmium, lead, and zinc in soils from Southwest Poland. J. Environ. Qual. 25:69-79.

Christensen, T.H., and P.M. Huang. 1999. Solid phase cadmium and the reactions of aqueous cadmium with soil surfaces. p. 65-96. In M.J. McLaughlin and B.R. Singh (ed.) Cadmium in soils and plants. Kluwer Academic Publ., Dordrecht, the Netherlands.

Dobrzanski, J., and H. Byrdziak. 1995. Impact of Polish copper industry on the environment. (In Polish, with English summary.) Zesz. Probl. Postpow Nauk Roln. 418:399-405.

He, Q.B., and B.R. Singh. 1993. Effect of organic matter on the distribution, extractability and uptake of cadmium in soils. J. Soil Sci. 44:641-650.

He, Q.B., and B.R. Singh. 1995. Cadmium availability to plants as affected by repeated applications of phosphorus fertilizers. Acta Agric. Scand. B 45:22-31.

Helmisaari, H.S., J. Jerome, H. Fritze, T. Nieminen, P. Palmgren, M. Salemaa, and I. Vanha-Majamaa. 1995. Copper in scots pine forests around a heavy metal smelter in southwestern Finland. Water Air Soil Pollut. 85:1727-1732.

Iyengar, S.S., D.C. Martens, and W.P. Miller. 1981. Distribution and plant availability of soil zinc fractions. Soil Sci. Soc. Am. J. 45: 735-739.

Jackson, M.L., C.H. Lim, and L.W. Zelazny. 1986. Oxides, hydroxides, and aluminosilicates. p. 101-150. In A. Klute (ed.) Methods of soil analysis. Part 1. 2nd. Agron. Monogr. 9. ASA and SSSA, Madison, WI.

Kabata-Pendias, A., and H. Pendias. 1992. Trace elements in soils and plants. 2nd ed. CRC Press, Boca Raton, FL.

Karczewska, A. 1996. Metal species distribution in top- and sub-soil in an area affected by copper smelter emissions. Appl. Geochem. 11:35-42.

Karczewska, A., L. Szerszen, and C. Kabala. 1998. Forms of selected heavy metals and their transformation in soils polluted by the emissions from copper smelters. Adv. GeoEcology 31:705-712.

Kennedy, V.H., A.L. Sanchez, D.H. Oughton, and A.P. Rowland. 1997. Use of single and sequential chemical extractants to assess radionuclide and heavy metal availability from soils for root uptake. Analyst 122:89-100.

Kim, N.D., and J.E. Fergusson. 1991. Effectiveness of a commonly used sequential extraction technique in determining the speciation of cadmium in soils. Sci. Total Environ. 105:191-209.

Kuo, S., P.E. Heilman, and A.S. Baker. 1983. Distribution and forms of copper, zinc, cadmium, iron, and manganese in soils near a copper smelter. Soil Sci. 135:101-109.

Ma, L.Q., and G.N. Rao. 1997. Chemical fractionation of cadmium, copper, nickel and zinc in contaminated soils. J. Environ. Qual. 26:259-264

Narwal, R.P., and B.R. Singh. 1998. Effect of organic materials on partitioning, extractability and plant uptake of metals in an alum shale soil. Water Air Soil Pollut. 103:405-421.

Narwal, R.P., B.R. Singh, and B. Salbu. 1999. Association of cadmium, zinc, copper, and nickel with components in naturally heavy metalrich soils studied by parallel and sequential extractions. Commun. Soil. Sci. Plant Anal. 30:1209-1230.

Ramos, L., L.M. Hernandez, and M.J. Gonzales. 1994. Sequential fractionation of copper, lead, cadmium and zinc in soils from Donana National Park. J. Environ. Qual. 23:50-57.

Reeuwijk, L.P. (ed.) 1995. Procedures for soil analysis. Tech. Paper 9. 5th ed. ISRIC, Wageningen, the Netherlands.

Roszyk, E., and L. Szerszen. 1988. Accumulation of heavy metals in arable layer of soils in the protection zones of copper smelters. Rocz. Glebozn. 39:135-156.

Salbu, B., T. Krekling, and D.H. Oughton. 1998. Characterization of radioactive particles in the environment. Analyst 123:843-849.

Shuman, L.M. 1985. Fractionation method for soil microelements Soil Sci. 140:11-22.

Shuman, L.M. 1990. Comparison of exchangeable aluminum, extractable aluminum, and aluminum in soil fractions. Can. J. Soil Sci. 70:263-267.

Singh, B.R. 1997. Soil pollution and contamination. p. 279-299. In R. Lal (ed.) Methods for assessment of soil degradation. CRC Press, Boca Raton, FL.

Singh, B.R., R.P. Narwal, A.S. Jeng, and A. Almas. 1995. Crop uptake and extractability of cadmium in soils naturally high in metals at different pH levels. Commun. Soil Sci. Plant Anal. 26:2123-2142.

Soil Survey Staff. 1998. Keys to soil taxonomy. 8th ed. USDA, Washington, DC.

Sposito, G., L.J. Lund, and A.C. Chang. 1982. Trace metal chemistry in arid zone field soils amended with sewage sludge. I. Fractionation of $\mathrm{Ni}, \mathrm{Cu}, \mathrm{Zn}, \mathrm{Cd}$ and $\mathrm{Pb}$ in solid phases. Soil Sci. Soc. Am. J. 46:260-264.

Szerszen, L., T. Chodak, and A. Karczewska. 1993. Areal, profile and time differentiation of heavy metal content in soils in the vicinity of copper smelters in LGOM, Poland. p. 279-281. In H.J.P. Eijackers (ed.) Integrated soil and sediment research. Kluwer Academic Publ., Dordrecht, the Netherlands.

Tessier, A., P.G.C. Campbell, and M. Bisson. 1979. Sequential extraction procedure for the speciation of particulate trace metals. Anal. Chem. 51:844-851. 